\title{
Impact of Biomass-Derived Contaminants on SOFCs with Ni/Gadolinia-Doped Ceria Anodes
}

\author{
P. V. Aravind, ${ }^{\mathrm{a}, \mathrm{z}}$ J. P. Ouweltjes, ${ }^{\mathrm{b}}$ N. Woudstra, ${ }^{\mathrm{a}}$ and G. Rietveld ${ }^{\mathrm{b}}$ \\ ${ }^{a}$ Section Energy Technology, Delft University of Technology, NL-2628 CA Delft, The Netherlands \\ ${ }^{b}$ Energy research Center of the Netherlands (ECN), NL-1755 ZG Petten, The Netherlands
}

The impact of biomass-derived contaminants on solid-oxide fuel cells (SOFCs) with Ni/gadolinia-doped ceria (GDC) anodes was investigated using electrochemical impedance analysis. Measurements were carried out with symmetric test cells under a singlegas atmosphere. The impact of $\mathrm{H}_{2} \mathrm{~S}, \mathrm{HCl}$, and naphthalene in the gas stream on the performance of Ni/GDC anodes are presented.

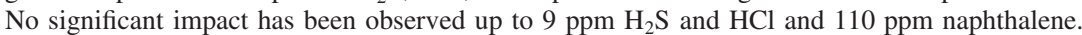
(C) 2007 The Electrochemical Society. [DOI: 10.1149/1.2820452] All rights reserved.

Manuscript submitted June 1, 2007; revised manuscript received November 8, 2007. Available electronically December 21, 2007.

Gasification is the conversion of biomass to a gaseous fuel by heating in a gasification medium such as air, oxygen, or steam. Biosyngas from gasification consists of a mixture of carbon monoxide, carbon dioxide, methane, hydrogen, water vapor, and impurities. These impurities are mainly $(i)$ particulate matter, (ii) tar, (iii) alkali metal compounds and other halides, (iv) sulfur compounds, and (v) nitrogen-containing compounds, especially ammonia. Once the biosyngas is cleaned to remove the contaminants to a level sufficient for solid oxide fuel cells (SOFCs), it can probably be used as an SOFC fuel. ${ }^{1,2}$ As the biomass is a sustainable primary energy source and is essentially $\mathrm{CO}_{2}$ neutral, such systems offer the potential for sustainable high-efficiency energy systems for the future.

Feeding SOFCs with biosyngas draws attention to many important issues. Because the fuel gets oxidized at the SOFC anode, chemical and physical interactions between the anode and the gas components are of critical significance. Different types of anodes have different kinds of interactions with these contaminants, and hence their tolerance levels for these contaminants may vary considerably. This, in turn, alters the choices for the required gascleaning devices when SOFCs with such anodes are connected to biomass gasifiers. Because these different types of anodes may have varying effectiveness in the conversion of the fuel, proper selection of the SOFCs with suitable anodes and gas-cleaning systems and appropriate operation parameters for them is of critical significance in the development of feasible and efficient designs of biomass gasifier-SOFC systems.

Conventional SOFC anodes contain substantial amounts of nickel. Nickel is widely considered as an attractive material for SOFC anodes because it is a good electronic conductor and catalytically active for the electrochemical oxidation of hydrogen. In order to increase the mechanical properties, nickel is mixed with an ionconducting material, most commonly yttria-stabilized zirconia (YSZ). Doped ceria, such as gadolinia- or samaria-doped ceria, is a mixed conductor under reducing conditions. It offers increased surface area for electrochemical reactions, unlike materials offering mainly ionic conductivity and low electronic conductivity, which limit the reactions to fuel/electrode/electrolyte boundaries. They are also expected to give better performance with fuels containing hydrocarbons. ${ }^{3}$ For this reason, anodes comprising gadolinia-doped ceria (GDC) and nickel were selected for experiments with biosyngas. These anodes are expected to show sufficient ionic and electronic conductivities at $1123 \mathrm{~K}$, which is the temperature considered in this study. ${ }^{4}$ Use of impedance spectroscopy as a tool for studying the effect of contaminants such as $\mathrm{H}_{2} \mathrm{~S}$ on SOFC anodes has been reported in the literature before. ${ }^{5}$ Because it is difficult to carry out experiments with all the contaminants in biosyngas, a few important contaminants were selected. The aim of the measurements was to evaluate the effect of the contaminants on SOFC anode performance in the short term. It is not intended to suggest that only these con-

${ }^{\mathrm{z}}$ E-mail: p.v.aravind@tudelft.nl taminants may have some sort of influence on anode performance. The evaluations suggested here in this paper are considered as a first step in the detailed studies required for full understanding of the influences of all the biomass-derived contaminants on short- and long-term SOFC performance.

It appears that the following group of contaminants present in biosyngas may influence SOFC performance and were selected for the present studies: (i) sulfur compounds, (ii) tars, and (iii) halides. Ammonia is not included in the studies because it is considered as a fuel for SOFCs. ${ }^{6}$ The influence of particulates is considered for future studies and is not included in this study.

For sulfur compounds, $\mathrm{H}_{2} \mathrm{~S}$ was taken as the representative compound because most of the sulfur in biosyngas was expected to be present as $\mathrm{H}_{2} \mathrm{~S} .{ }^{7} \mathrm{H}_{2} \mathrm{~S}$ is widely considered as one of the contaminants that can cause problems for SOFC operation. ${ }^{5,8}$ Previous studies indicated that even at $1 \mathrm{ppm}$ the presence ${ }^{5}$ of sulfur in fuel gas had a negative impact on the performance of SOFCs with nickel/ YSZ anodes. For halides, $\mathrm{HCl}$ was taken as the representative compound. Chlorine is expected to be present in the biosyngas, and whether it is present mainly as $\mathrm{HCl}$ or alkali halides may depend upon the reaction conditions inside the gasifier and the biomass feed employed. In the case of tar-related tests, naphthalene $\left(\mathrm{C}_{10} \mathrm{H}_{8}\right)$ was chosen as a representative contaminant. It is a member of the polycyclic aromatic hydrocarbon group of compounds which are commonly found in tars. This is also one of the tar compounds which may escape even the severest cleaning conditions that may occur in high-temperature catalytic tar-cleaning devices. ${ }^{9}$ For this reason, they are most likely present in biosyngas coming in contact with the anode.

\section{Experimental}

$\mathrm{Ni} / \mathrm{GDC}$ anodes prepared consisted of the following three layers: an adherence layer of $\mathrm{Gd}_{0.4} \mathrm{Ce}_{0.6} \mathrm{O}_{1.8}+2 \mathrm{~mol} \%$ Co adjacent to the electrolyte, a functional layer of $\mathrm{NiO} / \mathrm{Gd}_{0.1} \mathrm{Ce}_{0.9} \mathrm{O}_{1.95} 65 / 35$ wt $\%$ and finally a contact layer of $\mathrm{NiO}$. Anode functional layers with the given composition are expected to give sufficient ionic and electronic conductivities at $1123 \mathrm{~K}$. An adherence layer was added based on previous experience that such layers help to achieve improved contact between the electrolyte and the electrode functional layer. Finally, the NiO layer was added in order to achieve good electronic conductivity. The anodes were $22 \mathrm{~mm}$ in diameter and $35 \mu \mathrm{m}$ in thickness and were printed to $130-140 \mu \mathrm{m}$ thick $3 \mathrm{YSZ}$ electrolytes with $25 \mathrm{~mm}$ diameter and sintered in air at $1473 \mathrm{~K}$.

Ceramic supports with a thickness of $5 \mathrm{~mm}$ were kept on both sides of the test cells. Each of these supports had two layers, with each layer having several parallel channels of $1 \mathrm{~mm}$ width and $2.5 \mathrm{~mm}$ depth. Channels from these two layers were perpendicular to each other so that gas was easily distributed. Adjacent to the test cells, gold meshes and wires were used for electrical contact (gold is used as it is considered to be inert and is not expected to interact with the contaminants). The sample was kept in a single-gas chamber through which the fuel gas was passed. Humidified hydrogen at 


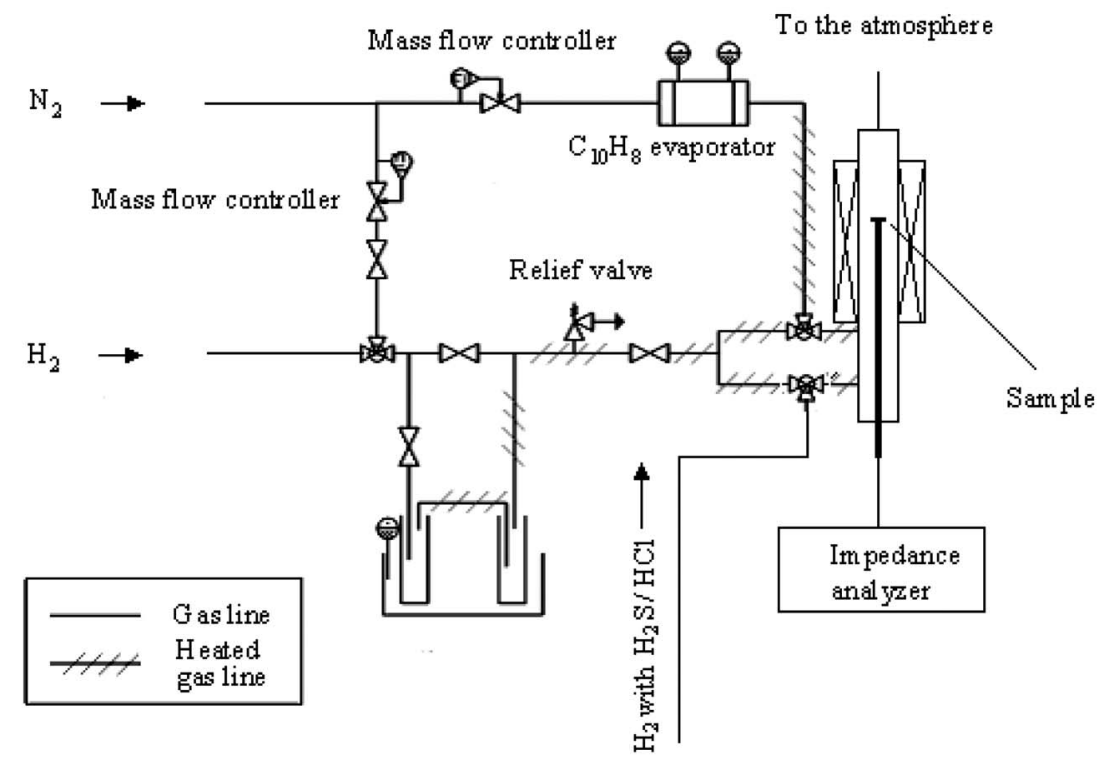

Figure 1. The test setup.

4.2 vol \% moisture was employed as fuel during the tests. Nitrogen was additionally used as an inert gas feed during heat-up, temperature stabilization, and shutdown periods, as well as a carrier flow for the experiments with naphthalene as the contaminant. When nitrogen was employed, during the impedance measurements, the gas mix entering the sample holder always had a humidity of $4.2 \%$. This was achieved either by humidifying the hydrogen-nitrogen mixture or by increasing the humidity of hydrogen stream to which dry nitrogen was added. A two-chamber bubble-type humidifier was employed, where the operating temperature of the humidifier unit controls the humidification extent. All gas feed lines downstream of the humidification unit were trace-heated in order to avoid condensation of $\mathrm{H}_{2} \mathrm{O}$. A K-type thermocouple on the sample surface was included to constantly monitor the anode operational temperature. Figure 1 shows the experimental setup.

Addition of the contaminant was performed differently in each experimental case. For $\mathrm{H}_{2} \mathrm{~S}$ and $\mathrm{HCl}$, hydrogen bottles containing a fixed fraction of these contaminants were used to supply the gas for addition to the humidified hydrogen flow. This addition was done after humidification and just before the gas mixture entered the sample holder. Prior to the experiments, at the sample-holder outlet, gas sampling was carried out for both cases in order to verify the contaminant concentrations. For $\mathrm{H}_{2} \mathrm{~S}$, sampling was carried out using tedlar gas-sampling bags and the $\mathrm{H}_{2} \mathrm{~S}$ concentration was analyzed using a gas chromatograph. Average $\mathrm{H}_{2} \mathrm{~S}$ content in the feed gas was observed as $148 \mathrm{ppm}$. $\mathrm{HCl}$ was collected at the sampleholder outlet by passing the gas through demineralized water in a washing bottle, and the chlorine content was determined using ion chromatograph. The average $\mathrm{HCl}$ content in the feed gas was observed as $159 \mathrm{ppm}$. For the purposes of the tar-related experiments, a separate naphthalene evaporator unit was employed. The device consisted of two heated chambers in series, each containing a fixed bed of solid naphthalene particles. As the gas feed passed through the chambers, it was saturated with naphthalene. The second chamber was kept at a lower temperature when compared to the first. The gas-flow scheme for the experiments with naphthalene is given in Fig. 1. Naphthalene concentration in the fed gas entering the sample holder was measured at each set point before the experiments. Sample gas was collected at the outlet of the sample holder and solid phase absorption method (SPA) was used for the sampling and analysis. The quantity of naphthalene in the collected sample was determined using a gas chromatograph with a flame ionization detector. These measured values of naphthalene concentrations were used for the analysis of the results. Teflon tubes were used for car- rying gas streams containing contaminants to the sample holder, and these tubes were flushed with the contaminated gas for several hours before the experiments.

Impedance measurements were performed with a Solartron frequency response analyzer 1255 in combination with a Solartron electrochemical interface 1287 . The measurements were carried out at zero bias in the frequency range between $0.1 \mathrm{~Hz}$ and $100 \mathrm{kHz}$ using a four-probe configuration with a signal amplitude of $10 \mathrm{mV}$.

After loading the sample in the quartz sample holder, heat-up was initiated with a dry nitrogen flow of $0.1 \mathrm{Nlt} / \mathrm{min}$ used as inert feed. Reduction of the anode sample was performed at $1123 \mathrm{~K}$ by gradually replacing nitrogen with humidified hydrogen over a period of $80 \mathrm{~min}$. The sample was then kept for $12-24 \mathrm{~h}$ in the humidified hydrogen flow for stabilizing the anode. The contaminant was then added to the fuel stream. In the case of the tar-related experiments, a separate nitrogen feed for the naphthalene evaporator was employed, which was then mixed with the primary hydrogen feed. Impedance-spectra acquisition was performed on each sample anode at intervals of $15 \mathrm{~min}$ for operation periods of 90-120 min. Separate samples were used for experiments with each of the contaminants. The inlet gas moisture percentage was kept at 4.2 vol \% in all cases. The summary of the tested conditions can be seen in Table I. Contaminant levels employed for the experiments were selected based on the possible cleaning levels that can be achieved when state-ofthe-art gas-cleaning systems are employed. It has been reported in the literature that it is possible to achieve sub-ppm levels of $\mathrm{H}_{2} \mathrm{~S}$ in

\begin{tabular}{l} 
Table I. SOFC-anode test conditions at $\mathbf{1 1 2 3} \mathbf{K}$. \\
\multicolumn{4}{c}{$\begin{array}{c}\text { Inlet } \\
\text { Carrier gas } \\
\text { (humidified at } \\
\text { Contaminant }\end{array}$} & $\begin{array}{c}\text { contaminant } \\
\text { concentration } \\
\text { (ppmv) }\end{array}$ & $\begin{array}{c}\text { Measurement } \\
\text { duration } \\
\text { (h) }\end{array}$ \\
\hline
\end{tabular}




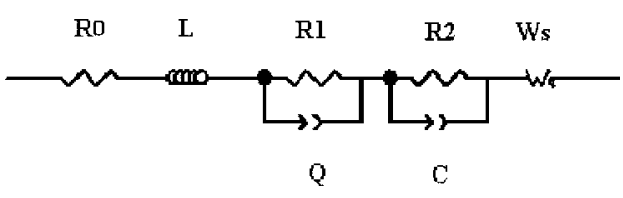

Figure 2. The equivalent circuit used for fitting.

fuel gas using state-of-the-art gas-cleaning methods. ${ }^{10}$ The same is true with $\mathrm{HCl}^{11}$ However, possible cleaning levels that can be achieved for tar components are considered to be higher at a few ppms to a few tens of ppm levels when state-of-the-art gas-cleaning methods are employed. ${ }^{2}$ For that reason, the quantity of naphthalene in the feed gas employed was at higher levels of a few tens of ppms.

\section{Results and Discussion}

The obtained impedance spectra are presented below. No attempt is made to identify all the processes involved in the electrochemical reactions at the anode. The observed spectra showed three separate arcs. The low-frequency arc of the spectra taken with SOFC anodes under symmetric test cells as employed in the present study is considered to originate from gas-phase processes. ${ }^{13,14}$ It is suggested that in experiments with symmetric test cells in single-gas atmosphere, diffusion limitations across a stagnant gas layer adjacent to the anode are dominant. In this work, the arc observed at the lowest frequency is attributed to diffusion limitation across such a stagnant layer assumed to be present at both sides of the anode. It is also suggested that the diffusion resistance is influenced by the gas composition. Other arcs probably originate from processes at the surface of, or in the bulk of, the anode material. Attributing the lowfrequency part of the spectra to diffusion is also in good agreement with the detailed analysis of the spectra carried out. ${ }^{95}$

Contaminants present in biosyngas at a few ppm levels are not expected to affect diffusion limitation across the stagnant gas layer (when there is no significant influence on the total anode performance and when there are no reforming or other reactions introducing significant gas-composition changes). For that reason, in the analysis of the results, we decided to give more attention to possible variations in the resistances associated with the high- and mediumfrequency arcs.

Obtained impedance spectra were fitted with the following circuit elements using the software Z-View. For processes 1 and 2, represented as semicircles (process 1 with a depressed semicircle), the equivalent subcircuit $(R Q)$ with a resistance $R$ and a constantphase element $Q$ in parallel was applied. The admittance of $\mathrm{Q}$ is $Y^{*}=Y_{0}(j \omega)^{n}$, where $Y_{0}$ is an adjustable admittance depending on the characteristics of the corresponding process, $j$ the imaginary unit, $\omega$ the angular frequency, and $n$ a frequency exponent. When $n$ is consistently unity, $Q$ represents a perfect capacitance. This was the case for semicircle 2 . For the third arc, one-dimensional diffusion in a stagnant layer of homogeneous gas mixture of finite thickness is assumed. Finite-length Warburg diffusion (with a notation $W s$ as represented in Z-View) with admittance $Y^{*}$ $=Y_{0} \sqrt{j \omega} \operatorname{coth}(B \sqrt{j \omega})$ is used in this case. The admittance parameter $Y_{0} \propto \sqrt{D_{\text {eff }}}$ and $D_{\text {eff }}$ is the effective diffusion coefficient of the diffusing reactant in the given gas mixture. The parameter $B$ is given as $B=l / \sqrt{D_{\text {eff }}}$, where $l$ is the thickness of the stagnant gas layer. ${ }^{14}$ The diffusion resistance is given by $R_{\mathrm{D}}=B / Y_{0}$ and is represented by $W R$ in the following analysis. Identical rate-limiting steps are assumed to occur on both the electrodes, and hence the resistances obtained are assumed to be the sum of the corresponding values on each of the electrodes taken separately.

Impedance spectra were fitted with an $R 0 L-R 1 Q p-R 2 C p-W s$ equivalent circuit as given in Fig. 2. $R 0$ is a series resistance, which is expected to be the sum of various resistances like the electrolyte and contact resistances and is denoted as $S R$ hereafter. This resis-

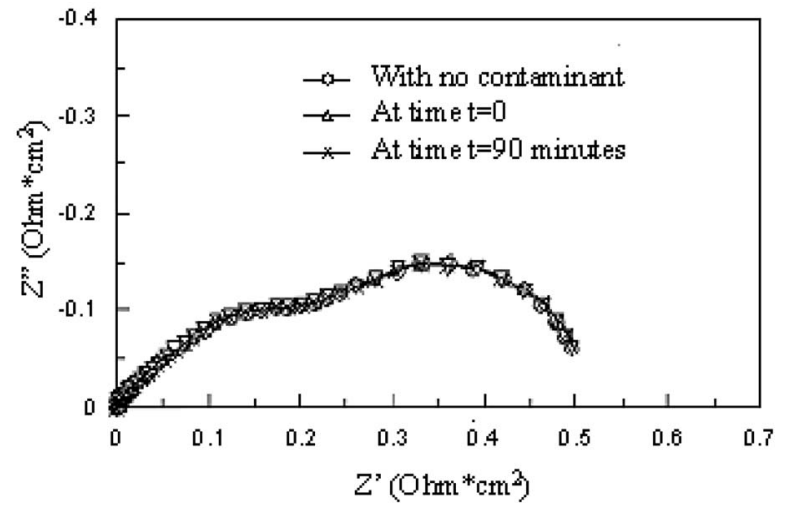

Figure 3. Impedance spectra obtained at $1123 \mathrm{~K}$ prior to the contaminant addition, at the beginning of the experiment (at $t=0$ ) and after $90 \mathrm{~min}$ exposure (at $t=90 \mathrm{~min}$ ) to $9 \mathrm{ppmv}_{2} \mathrm{~S}$ (adjusted for series resistance).

tance is not expected to contribute to the anodic polarization. $\mathrm{L}$ is considered as an inductance associated with the measuring system and is ignored in the present analysis. $R 1$ and $R 2$ represent different circuit elements as given above, and the diffusion resistance $W R$ is obtained from the fit parameters for the circuit element Ws. Total anodic polarization is considered as the sum of $R 1, R 2$, and $W R$.

Electrochemical impedance spectra were recorded with all the samples using clean humidified hydrogen as feed gas before the experiments with contaminants. For the following discussion, test cell 1 means the one used for experiments with $\mathrm{H}_{2} \mathrm{~S}$, test cell 2 means the one used for experiments with $\mathrm{HCl}$, and test cell 3 means the one used for experiments with naphthalene. The spectra recorded with test cell 1 under clean feed gas looked slightly different from the spectra recorded with samples 2 and 3 at the high-frequency region (Fig. 3, 5, and 7). Similar differences also appeared with the fitted values. For process $1, n$ values appeared to be near 1 for test cells 2 and 3. However, for test cell $1, n$ appeared to be around 0.55 . Similarly, the values for $R 1$ appeared to be comparable for test cells 2 and 3 but significantly higher for test cell 1 (Fig. 4, 6, and 8). We have no clear explanation for this variation. This may originate from the variations that occurred during the manufacturing of these cells (variations in quantities of slurries that were deposited during screen printing, etc.) or might be due to any other undetected inaccuracies in the experimental methods. The second process consistently showed an $n$ value of 1 for experiments with all the samples. However, $R 2$ was observed to be lower (approximately by half) for test cell 1 when compared to test cells 2 and 3 .

The third process consistently showed the behavior of gas-phase diffusion and had comparable values for all the test cells under humidified hydrogen. Diffusion impedance was comparatively higher for the experiments with naphthalene, as the carrier gas used for naphthalene experiments was a humidified hydrogen-nitrogen mixture (75\% hydrogen and $25 \%$ nitrogen), whereas the carrier gas used in the other experiments was humidified hydrogen. The introduction of higher fractions of nitrogen molecules with a higher molecular weight when compared to hydrogen is expected to cause this. Figure 7 also shows the difference between the spectra recorded with the same sample with humidified hydrogen and humidified hydrogen-nitrogen mixture.

However, for studying the influence of the contaminants, observed variations between test cells are ignored. What is looked at is the differences occurring with the spectra recorded with the same test cell before and after the exposure to contaminated gas.

Influence of $\mathrm{H}_{2} \mathrm{~S}$.- From the experiments with $\mathrm{H}_{2} \mathrm{~S}$, impedance spectra obtained prior to the contaminant addition, at the beginning of the experiment, and after 90 min exposure to the contaminated gas (with 9 ppmv $\mathrm{H}_{2} \mathrm{~S}$ ) are shown in Fig. 3. Variations in the resistance values associated with different circuit elements at different 


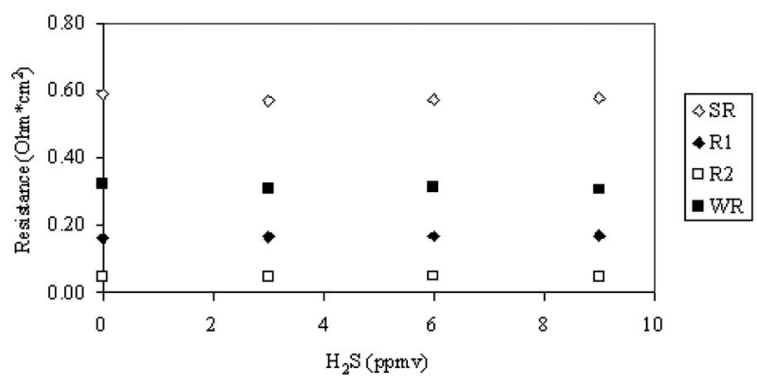

Figure 4. $R$ values of different circuit components with different levels of $\mathrm{H}_{2} \mathrm{~S}$ addition at $1123 \mathrm{~K}$ after fitting with the proposed equivalent circuit.

levels of $\mathrm{H}_{2} \mathrm{~S}$ addition are presented in Fig. 4. With contamination with $\mathrm{H}_{2} \mathrm{~S}$ no significant variation was observed in the total anodic polarization. There was no gradual variation in the values for the circuit model components $R 2$ and $W R$. However, there was a small gradual increase for the resistance $R 1$ with increased $\mathrm{H}_{2} \mathrm{~S}$ dosing levels. With $9 \mathrm{ppm} \mathrm{H}_{2} \mathrm{~S}$, the observed increase of $R 1$, which probably originated from a surface process, was $4.5 \%$ of the value with clean humidified hydrogen. However, this variation, which may even be due to uncertainties in measurements, was not sufficient to exert any influence on the total anodic polarization.

This result is interesting in comparison with the previous results indicating deterioration in the performance of $\mathrm{Ni} / \mathrm{YSZ}$ anodes even with $1 \mathrm{ppm} \mathrm{H}_{2} \mathrm{~S}$ in the fuel gas. The limitation with Ni/YSZ anodes could be the small active anode surface for catalytic electrochemical oxidation of the fuels. At concentrations around a few $\mathrm{ppm}_{2} \mathrm{~S}$, it is said that the possible performance degradation of the anode occurs mainly because of selective adsorption of $\mathrm{H}_{2} \mathrm{~S}$ on active sites near or on triple-phase boundaries. The fact that no significant impact of sulfur was observed on the Ni/GDC anodes could be because even when the nickel surface is covered with $\mathrm{H}_{2} \mathrm{~S}$, a large surface area of doped ceria is still electrocatalytically active. Even when contaminated due to $\mathrm{H}_{2} \mathrm{~S}$ adsorption on the surface, nickel can probably continue to act as a good electronic conductor. In fact, such a possibility was suggested in early studies. ${ }^{16}$ This result also agrees well with the results from current-voltage measurements carried out on a complete cell with Ni/GDC anode, reported elsewhere by the same authors, ${ }^{17}$ in which no impact of $\mathrm{H}_{2} \mathrm{~S}$ addition was observed on hydrogen oxidation for up to $9 \mathrm{ppm}$ of $\mathrm{H}_{2} \mathrm{~S}$ in the feed gas.

Influence of $\mathrm{HCl}$ - - From the experiments with $\mathrm{HCl}$, impedance spectra obtained prior to the contaminant addition, at the beginning of the experiment, and after $90 \mathrm{~min}$ exposure to the contaminated

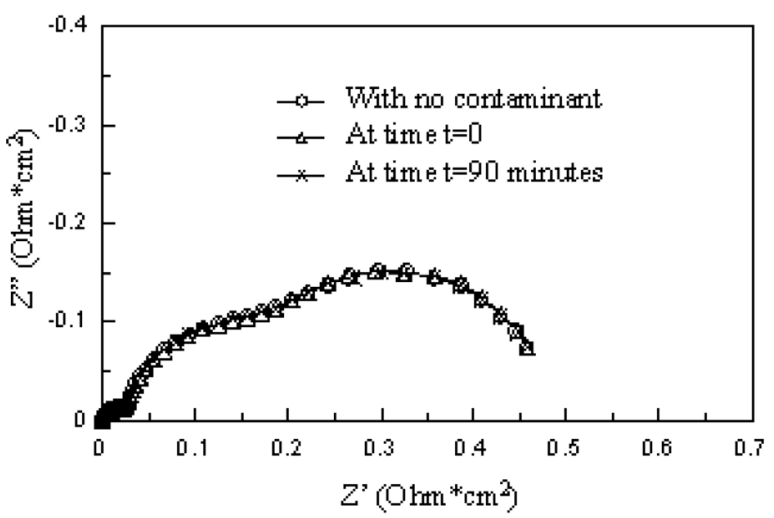

Figure 5. Impedance spectra obtained at $1123 \mathrm{~K}$ prior to the contaminant addition, at the beginning of the experiment (at $t=0$ ), and after $90 \mathrm{~min}$ exposure (at $t=90 \mathrm{~min}$ ) to $9 \mathrm{ppmv} \mathrm{HCl}$ (adjusted for series resistance).

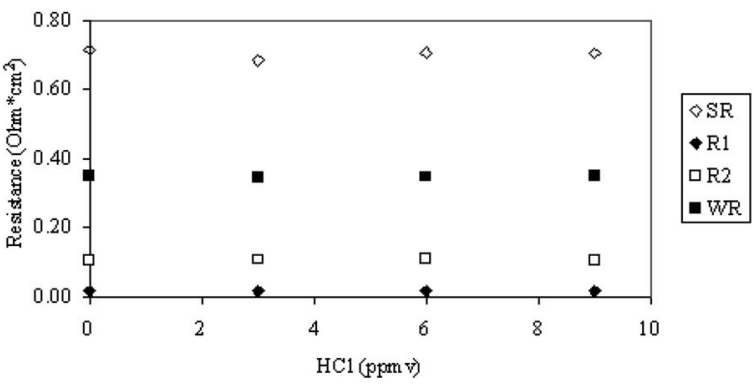

Figure 6. $R$ values of different circuit components with different levels of $\mathrm{HCl}$ addition at $1123 \mathrm{~K}$ after fitting with the proposed equivalent circuit.

gas (with 9 ppmv $\mathrm{HCl}$ ) are shown in Fig. 5. Variations in the resistance values associated with different circuit elements at different levels of $\mathrm{HCl}$ addition are presented in Fig. 6. With contamination with $\mathrm{HCl}$, no significant variation was observed in the resistance values associated with any of the circuit elements. This agrees well with the fact that no significant chemical interaction between $\mathrm{HCl}$ and anode materials (nickel and ceria), which may result in deposition of solid or liquid products on the anode surface, is expected at these levels of contaminant presence in the fuel gas. The results indicate that $(i)$ anode composition and structure are not significantly altered due to chemical or physical interactions between the contaminants and the anode materials and (ii) the anode is still electrocatalytically active for hydrogen oxidation.

Influence of naphthalene.- From the experiments with naphthalene, impedance spectra obtained prior to the contaminant addition, at the beginning of the experiment, and after $120 \mathrm{~min}$ exposure to the contaminated gas (with 110 ppmv naphthalene) are shown in Fig. 7. Variations in the resistance values associated with different circuit elements at different levels of naphthalene addition are presented in Fig. 8. Unlike the experiments with $\mathrm{H}_{2} \mathrm{~S}$ and $\mathrm{HCl}$, there was a gradual increase of $2.9 \%$ for total anodic polarization when the level of naphthalene contamination increased from zero to $110 \mathrm{ppm}$. This was probably caused mainly because of a similar increase of $2.9 \%$ in values of $W R$, which is difficult to explain based on the available information because gas-phase diffusion processes are not expected to be influenced by ppm levels of contamination (unless there is tar reforming). Partial reforming of tar fed at the concentration levels mentioned in this paper may cause variations in $\mathrm{H}_{2}$ and $\mathrm{H}_{2} \mathrm{O}$ concentrations in the carrier gas by a few hundred ppmvs, and this may cause slight variations in the diffusion resistance. ${ }^{14,15}$ However, such a possibility needs to be studied in

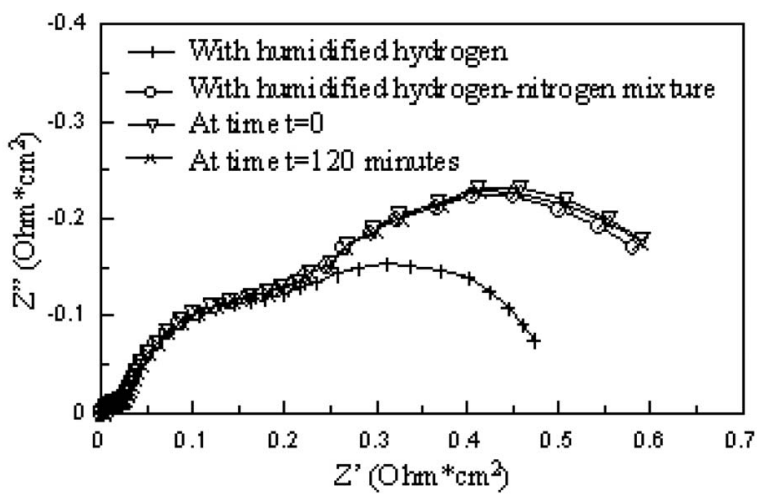

Figure 7. Impedance spectra obtained at $1123 \mathrm{~K}$ prior to the contaminant addition with humidified hydrogen and humidified hydrogen-nitrogen mixture, at the beginning of the experiment (at $t=0$ ), and after 90 min exposure (at $t=120 \mathrm{~min}$ ) to $110 \mathrm{ppmv}$ naphthalene (adjusted for series resistance). 


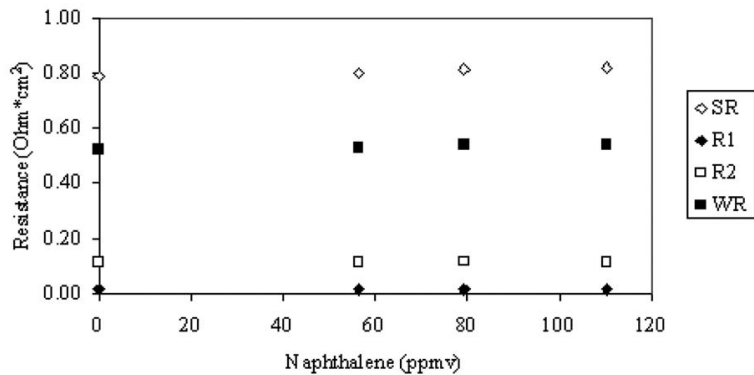

Figure 8. $R$ values of different circuit components with different levels of naphthalene addition at $1123 \mathrm{~K}$ after fitting with the proposed equivalent circuit.

detail before final conclusions can be reached. It is also possible that the observed increase of the diffusion-resistance values $(W R)$ could be attributed to measurement inaccuracies.

There was an increase of $6.7 \%$ for the resistance $R 1$ between the measurements with no naphthalene and the one with $56.5 \mathrm{ppm}$ naphthalene. However, there was no further increase for $R 1$ when the naphthalene contamination level was increased from 56.5 to $110.3 \mathrm{ppm}$. Instead, it stayed almost constant with a small decrease of $1 \%$. The observed increase in $R 1$ value, which is thought to have originated from surface processes, may or may not be from surface contamination or experimental uncertainties. Further research is necessary to understand this completely. For the reasons mentioned above, it shall be concluded that no significant degradation in SOFC anode performance is expected when the anodes are fed for short time periods with hydrogen gas containing naphthalene up to around $110 \mathrm{ppm}$ level.

Inspection of the sample after tests did not reveal any visible carbon deposition on the anode surface. This observation is supported by the fact that a few ppm of naphthalene in feed gas is in a thermodynamically safe operation range with respect to carbon deposition. A $\mathrm{C}-\mathrm{H}-\mathrm{O}$ ternary diagram indicating that the given composition is thermodynamically safe with respect to carbon deposition is shown in Fig. 9. The point representing the composition with the highest naphthalene level employed in the experiments (110 ppm naphthalene in humidified $\mathrm{H}_{2} / \mathrm{N}_{2}$ mixture) is well below the solid carbon line shown in the figure, below which no carbon deposition is expected (mole fractions shown are on nitrogen free basis).

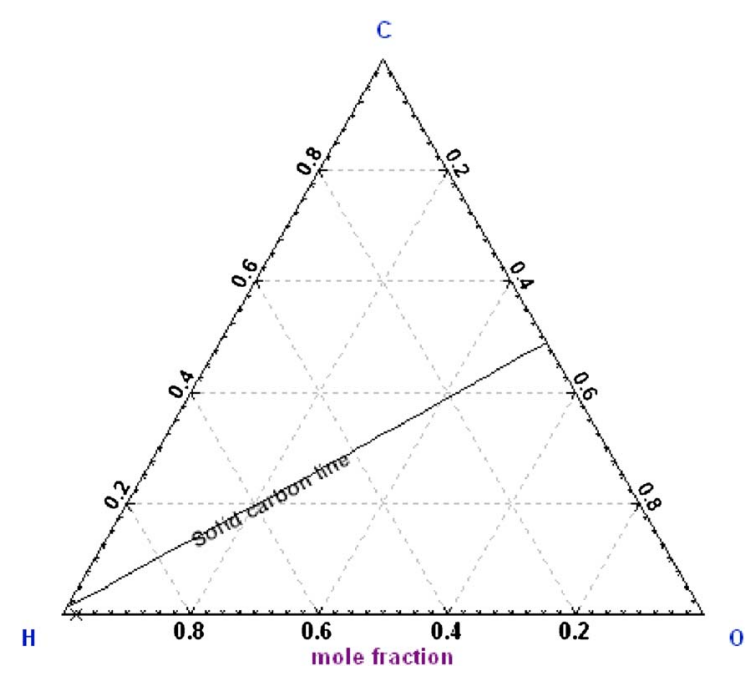

Figure 9. $\mathrm{C}-\mathrm{H}-\mathrm{O}$ ternary diagram indicating the carbon deposition possibilities (the point marked with an $\mathrm{X}$ at the bottom left corner indicates the composition of carrier gas with $110 \mathrm{ppmv}$ naphthalene).
As can be seen from the results of this experimental campaign, $\mathrm{Ni} / \mathrm{GDC}$ anode samples proved reasonably tolerant to naphthalene up to a few tens of ppm in the feed gas. It has been reported in literature that the cleaning limits that can be achieved for tar removal from biosyngas with suitable sorbents is up to a few ppm levels to a few tens of ppms. It has also been reported in the literature that tar-rich biosyngas from a gasifier did not cause any problem with SOFC operation during a $100 \mathrm{~h}$ experiment. ${ }^{18}$ Hence, it shall be assumed that reasonable performance can be expected from the SOFCs during operation with biosyngas with few ppms of naphthalene present. However, comparatively detailed studies are required to confirm these results and are recommended for detailed future research.

\section{Conclusions}

The impact of three different contaminants present in biosyngas on the performance of SOFC Ni/GDC anode has been investigated. The impedance measurements indicate that these contaminants, i.e., $\mathrm{H}_{2} \mathrm{~S}, \mathrm{HCl}$, and naphthalene, probably have no significant impact on the Ni/GDC anode performance with humidified hydrogen, at few ppm levels expected in biosyngas after cleaning with potentially viable gas-cleaning technologies. Hence, it is recommended that detailed and long-term evaluation of the influences of theses contaminants on SOFC performance be carried out in detail. If the trends observed during the short-term tests are confirmed with long-term experiments, it offers an excellent opportunity for the realization of sustainable high-efficiency power plants with biomass gasifiers and SOFCs.

\section{Acknowledgments}

The authors acknowledge partial financial support for this work from the European Commission through the project Biocellus. P.V.A. also acknowledges the support of W. de Jong and support and advice from Professor H. Spliethoff (TU Munich) and Professor J. Schoonman (TU Delft)

Delft University of Technology assisted in meeting the publication costs of this article.

\section{References}

1. P V Aravind, J. P Ouweltjes, E de Heer, N. Woudstra, and G. Rietveld, in Solid Oxide Fuel Cells (SOFC IX), S. C. Singhal and J. Mizusaki, Editors, PV 2005-07, p. 1459, The Electrochemical Society Proceedings Series, Pennington, NJ (2005).

2. S. Baron, N. Brandon, A. Atkinson, B. Steele, and R. Rudkin, J. Power Sources, 126, 58 (2004).

3. W. Z. Zhu and S. C. Deevi, Mater. Sci. Eng., A, 362, 228 (2003).

4. M. Mogensen, N. M. Sammes, and G. A. Tompsett, Solid State Ionics, 129, 63 (2000).

5. Y. Matsuzaki and I. Yasuda, Solid State Ionics, 132, 261 (2000)

6. N. Dekker and B. Rietveld, in The Sixth European Solid Oxide Fuel Cell Forum Proceedings, p. 1524, European Fuel Cell Forum (2004).

7. E. Kurkela, J. Laatijainen-Luntama, P. Stahlberg, and A. Morlanen, Pressurized Fluidized-Bed Gasification Experiments with Wood, Peat and Coal at VTT in 19911994, Part 3 Gasification of Danish Wheat Straw and Coal, 291, VTT Publications, Espoo, Finland (1996).

8. S. E. Veyo, Final Technical Report, DE-AC21-89MC26355-02 (DE00774909), U.S. Department of Energy, Washington, D.C. (1998).

9. P. Simell, J. Leppälahti, and E. A. Kurkela, Fuel, 74, 938 (1995).

10. W. F. Elseviers and H. Verelst, Fuel, 78, 601 (1999).

11. G. N. Krishnan, R. P. Gupta, A. Canizales, S. Shelukar, and R. E. Ayala, Removal of Hydrogen Chloride from Hot Coal Gas Streams, 1st ed., High Temperature Gas Cleaning, p. 405, Instiut für Mechanischle Verfaherstechnik and Mechanik, Karlsruhe, Germany (1996).

12. D. Dayton, Milestone Completion Report NREL/TP-510-32815, National Renewable Energy Laboratory, Golden, CO (2002).

13. W. G. Bessler, J. Electrochem. Soc., 153, A1492 (2006).

14. S. Primdahl, Ph.D. Thesis, University of Twente and Ris $\emptyset$ National Laboratory, The Netherlands and Denmark (1999).

15. P. V. Aravind, Ph.D. Thesis, Delft University of Technology, Delft, The Netherlands (2007)

16. S. C. Singhal, R. J. Ruka, J. E. Bauerle, and C. J. Spengler, Anode Development for Solid Oxide Fuel Cells, United States Department of Energy (1986).

17. J. P. Ouweltjes, P. V. Aravind, N. Woudstra, and G. Rietveld, J. Fuel Cell Sci. Technol., 3, 495 (2006)

18. S. Stucki and S. Biollaz, in The Fuel Cell World, European Fuel Cell Forum, Lucerne, Switzerland (2004) 